\title{
APPENDIX V. GEOPHYSICAL APPENDIX
}

Robert B. Whitmarsh, National Institute of Oceanography, Wormley, Godalming, Surrey, United Kingdom

The purpose of this appendix is to show the seismic reflection profiles obtained with an air-gun system by Glomar Challenger during Leg 23. Above each profile hourly time marks, the date, and day number are given (note that time increases from right to left). Beneath the profiles, course changes of 10 degrees or more are indicated by an asterisk. Since the horizontal time scale is variable, the ship's speed over the ground is given in knots $( \pm 0.5)$ and appears as a circled figure with short vertical bars indicating speed changes. From these data the actual horizontal distance represented by any portion of the profile can be computed. The vertical scale of the profiles is constant at 5 seconds, (two-way time) $=2$ inches.

The track followed by Glomar Challenger is shown on the small-scale chart Figure 1, preceding the seismic profiles. 


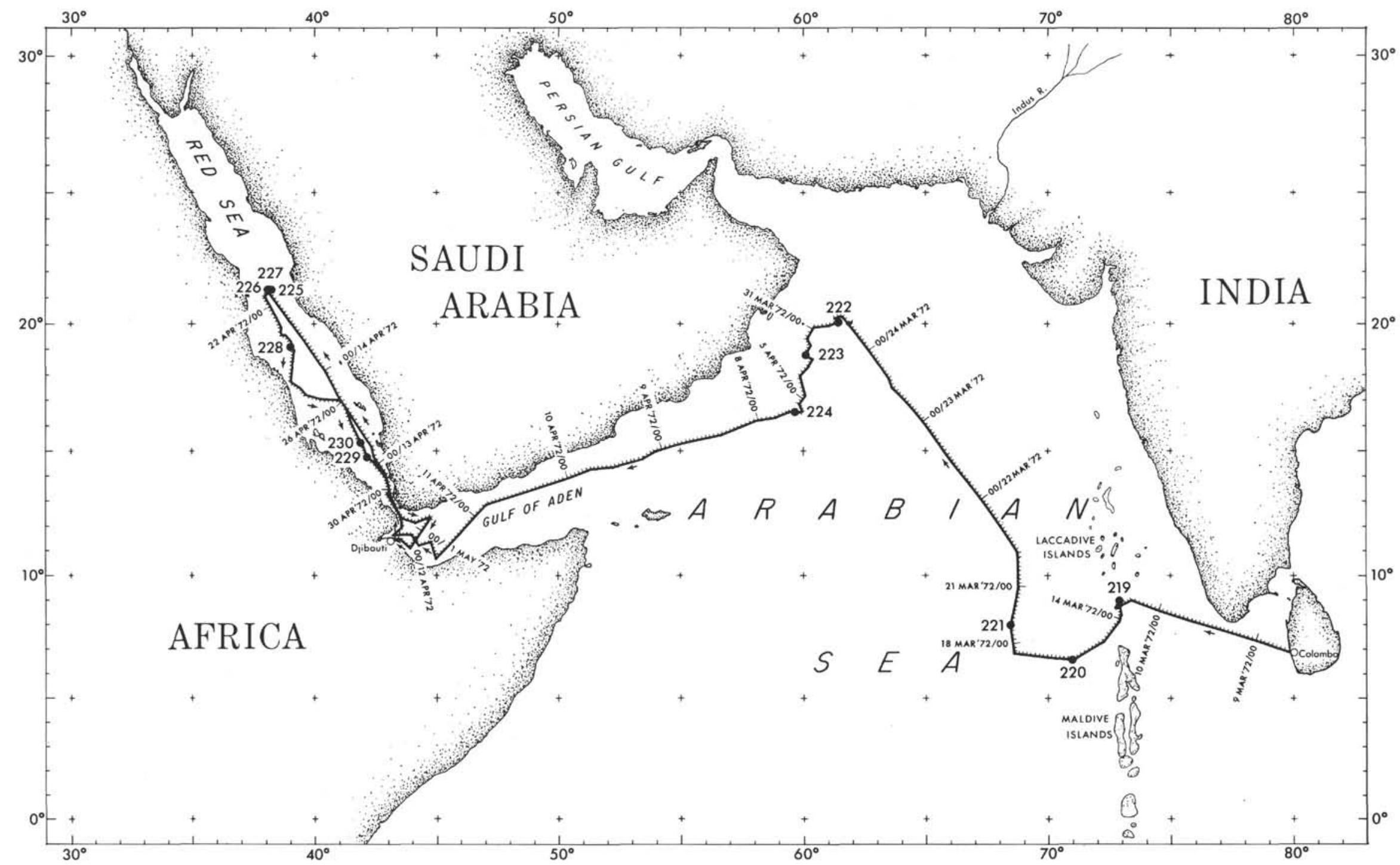

Figure 1. Track Chart of the Glomar Challenger during its Leg 23 Cruise. 

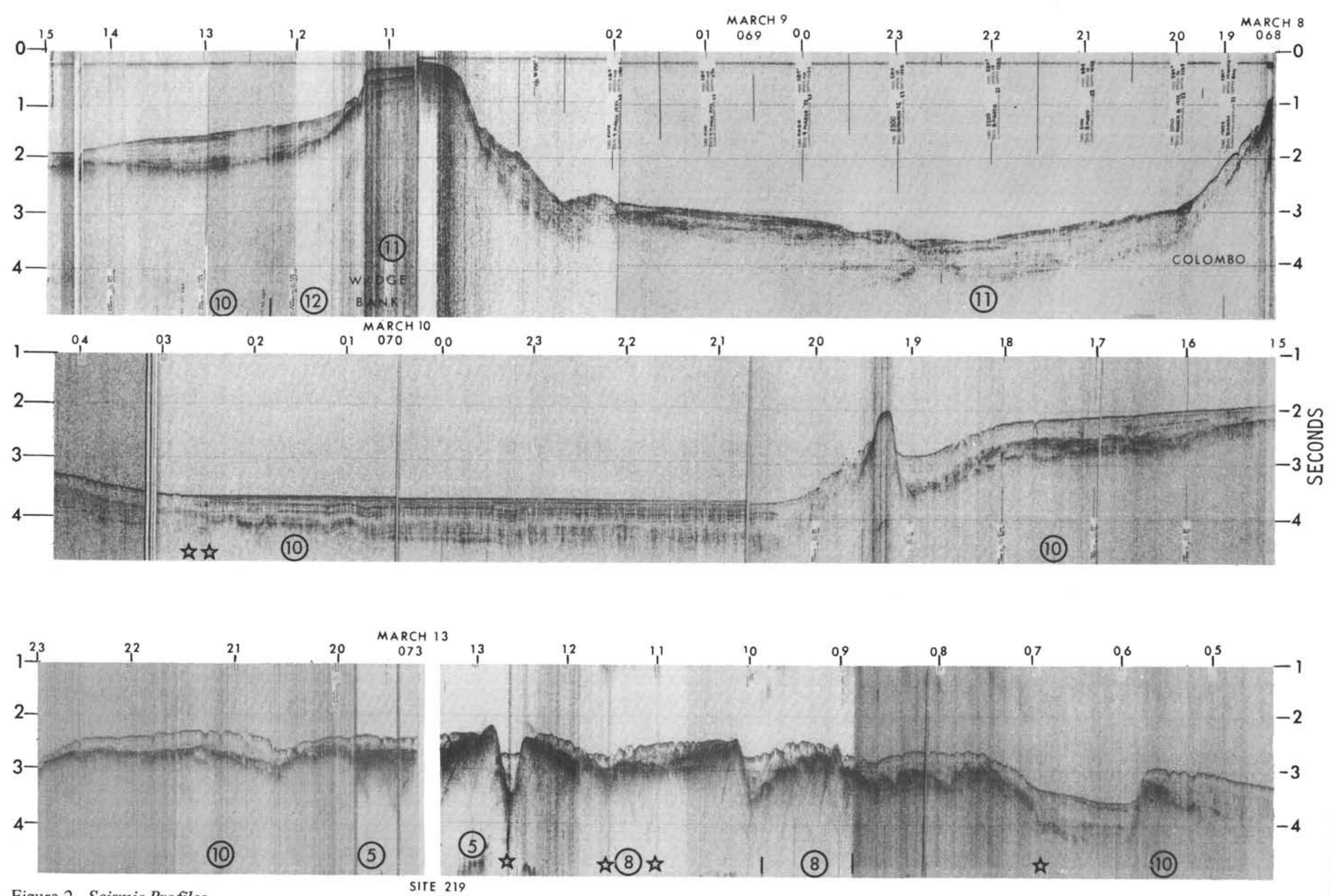
ิㅗำ
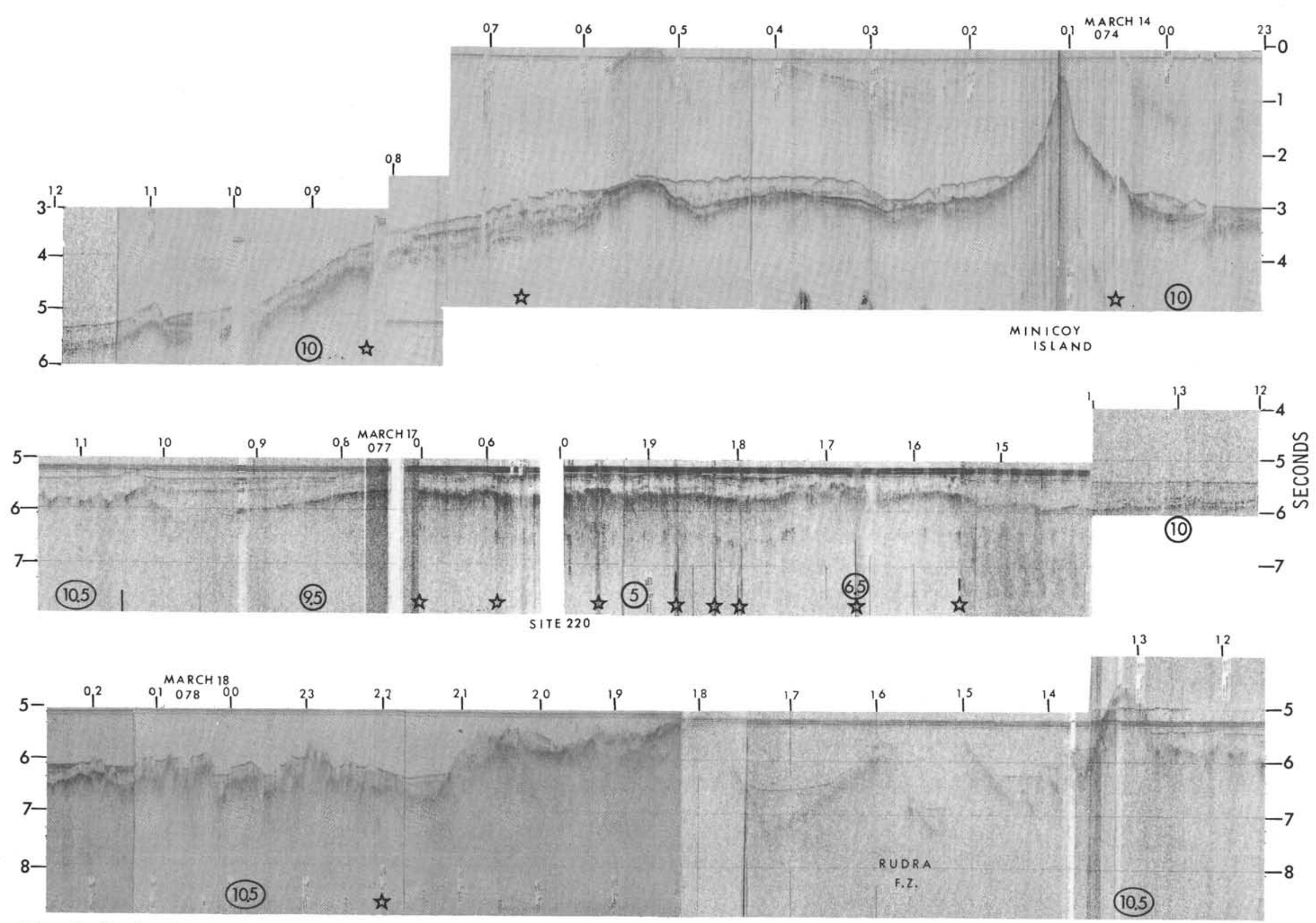

Figure 2. Continued 


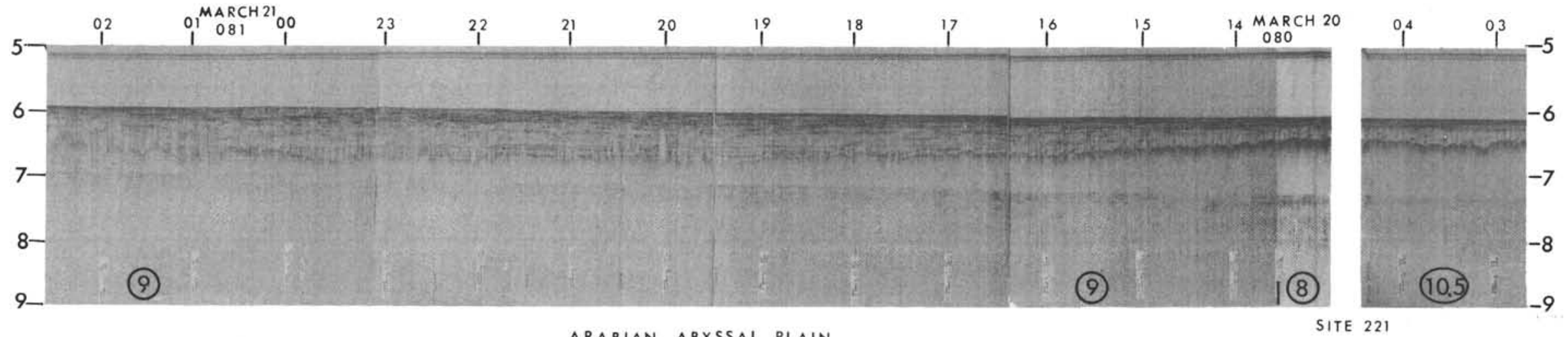

ARABIAN ABYSSAL PLAIN
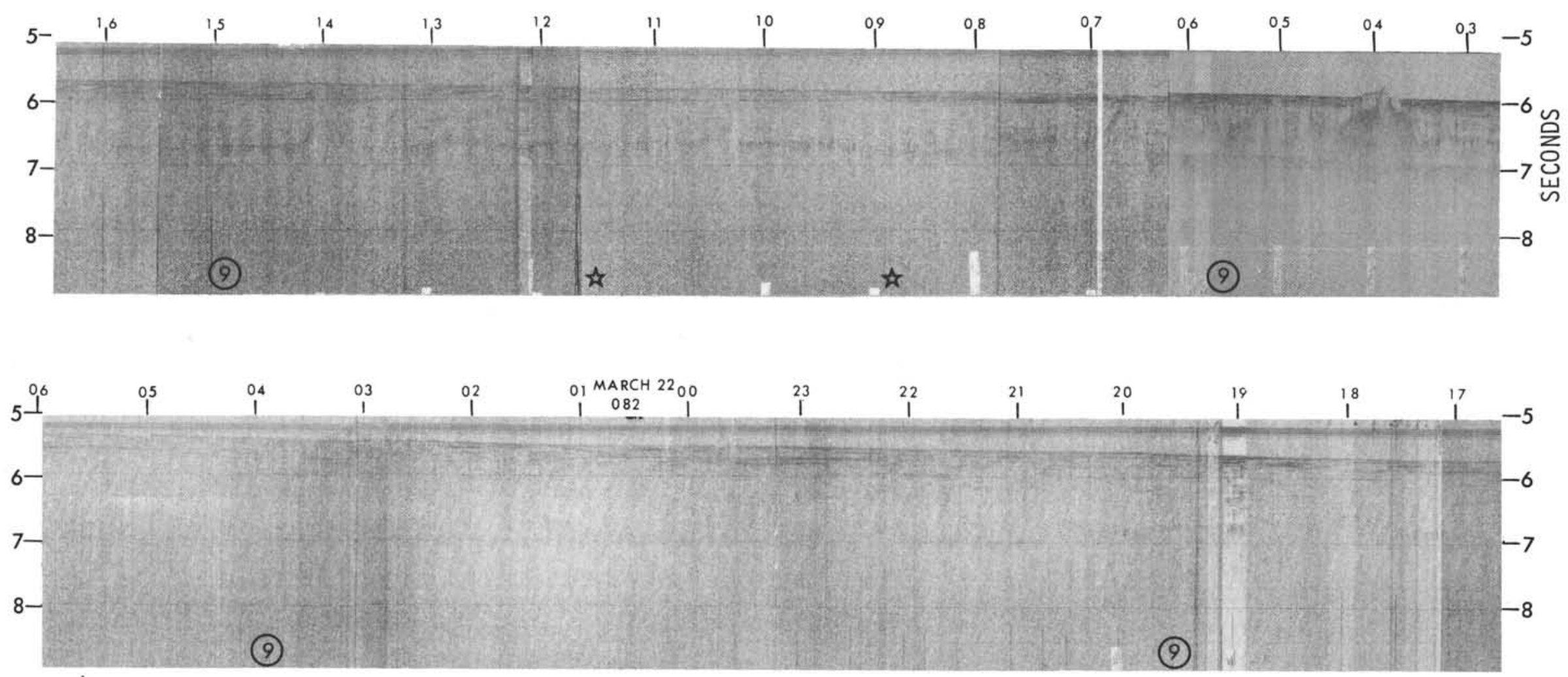

$\overrightarrow{\mathrm{\omega}}$ 

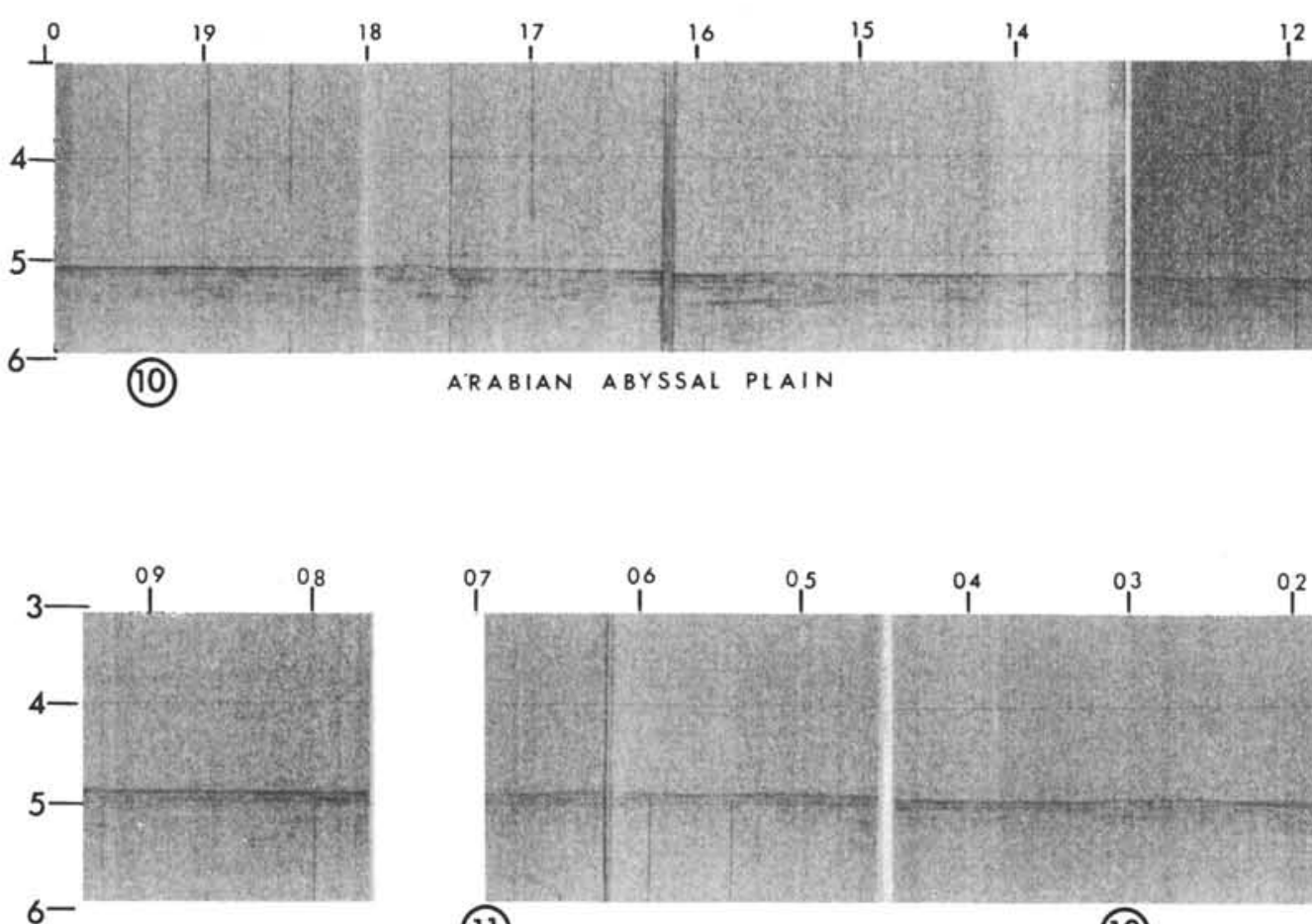

$1^{2}$

ARABIAN ABYSSAL PLAIN

6-

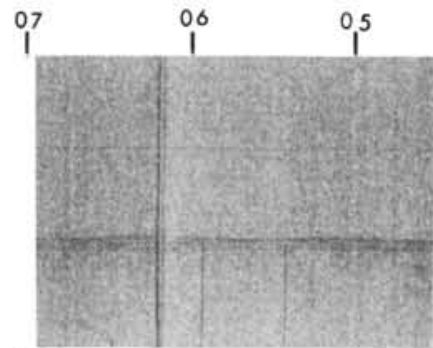

(11)
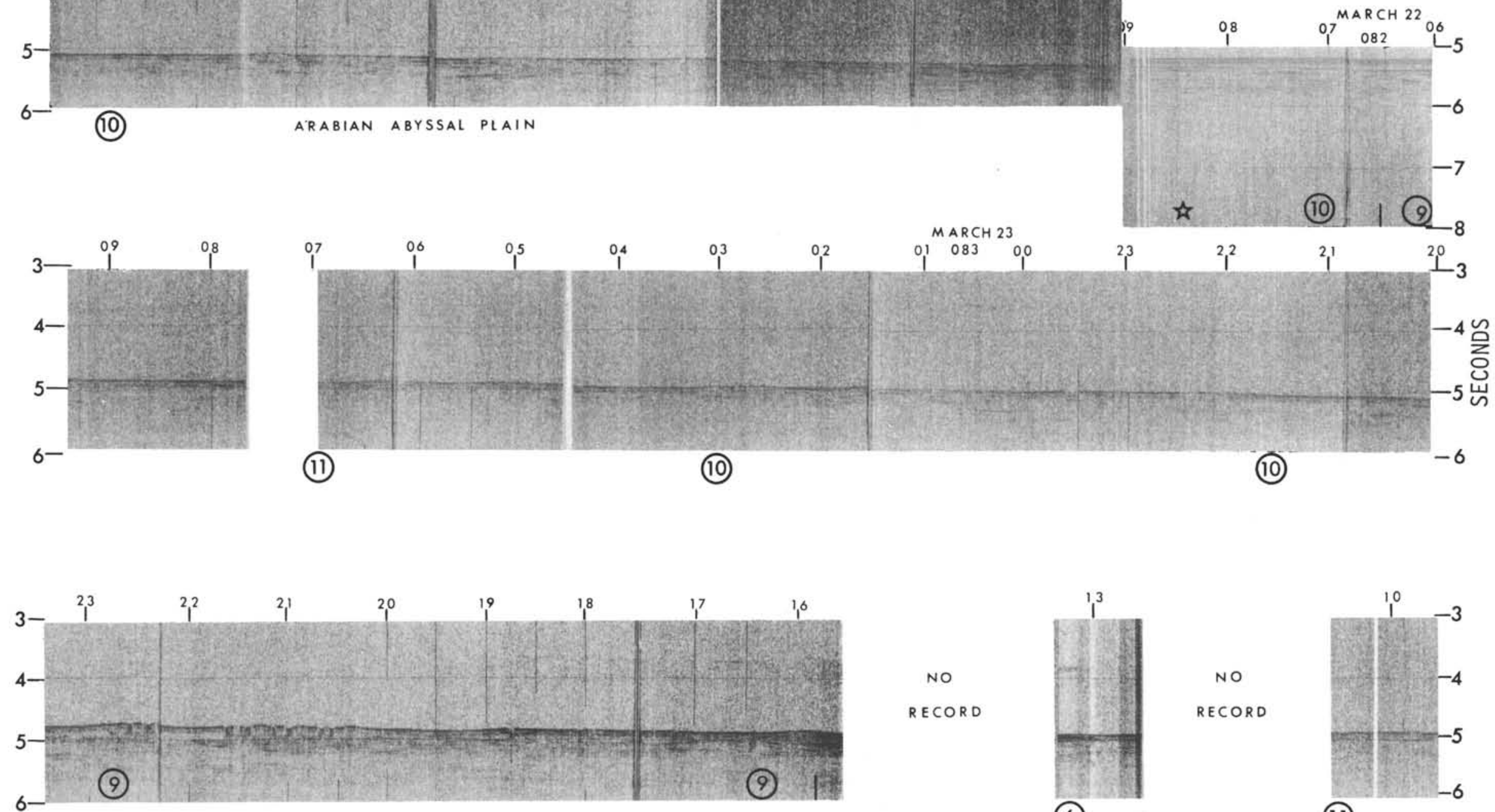

NO

RECORD

Figure 2. Continued
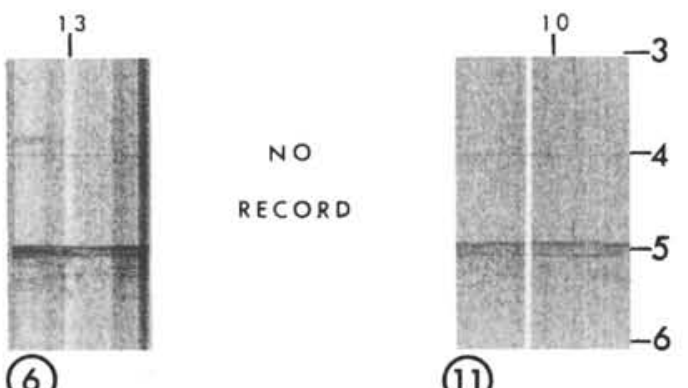

(11)

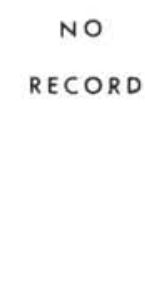



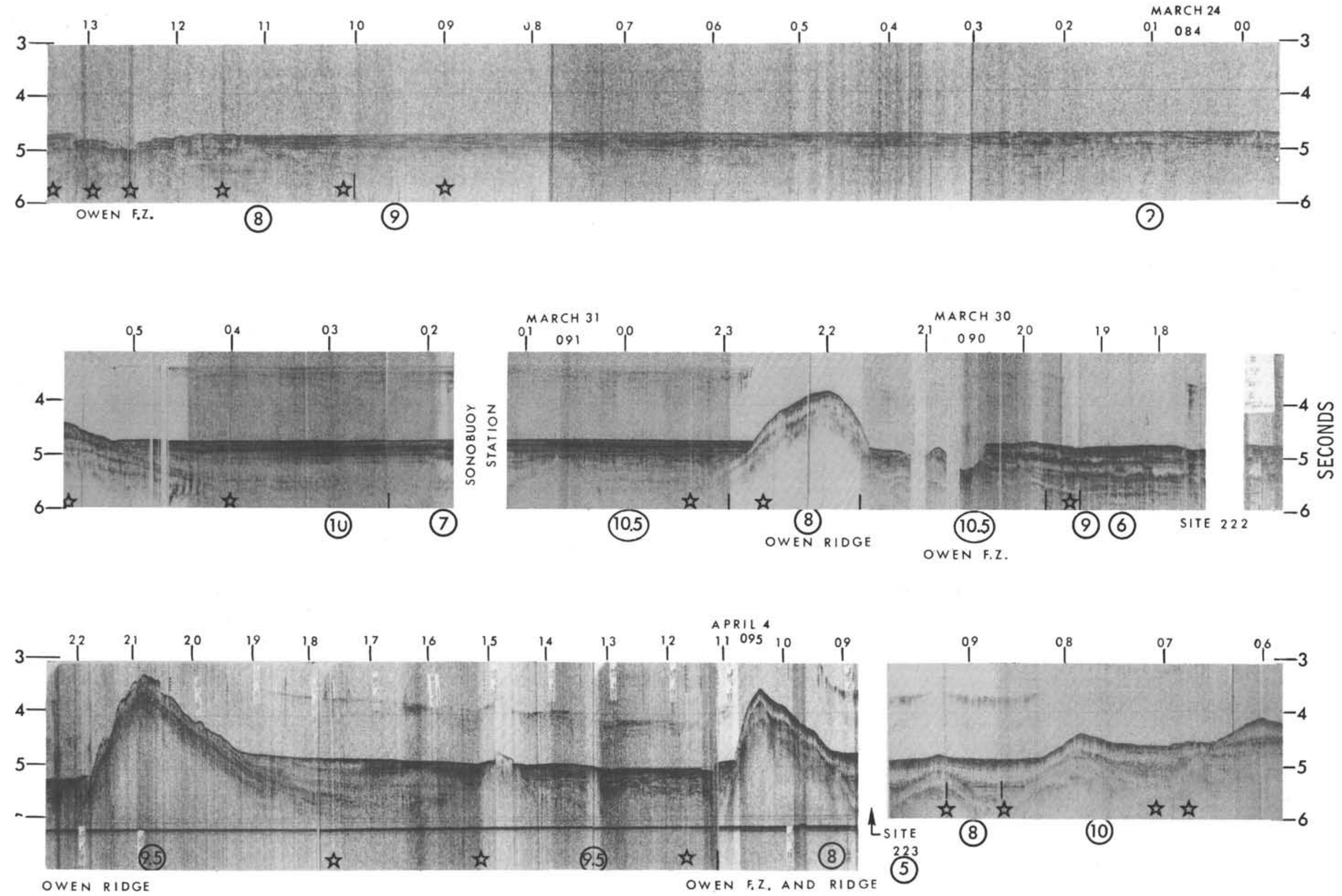

ت Figure 2. Continued 
ล
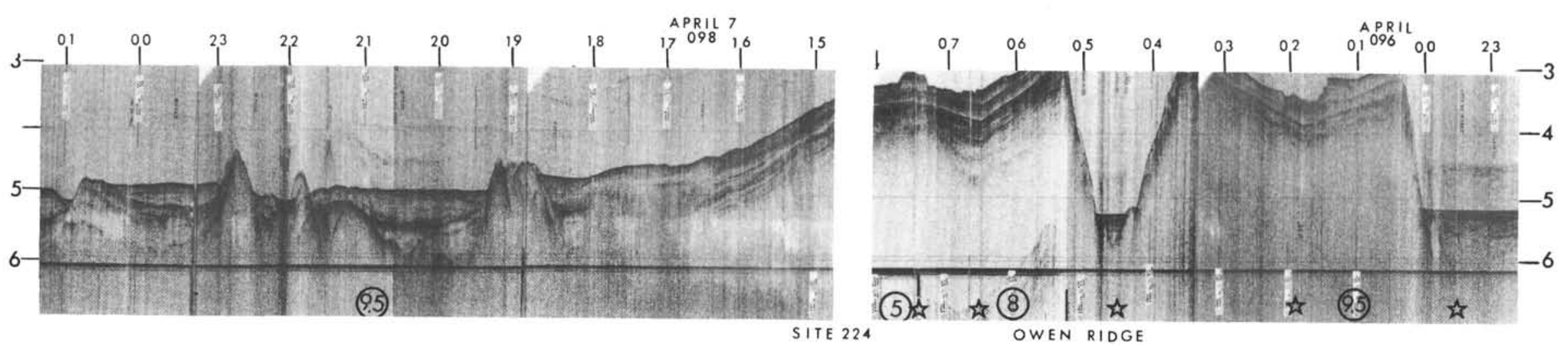

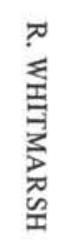
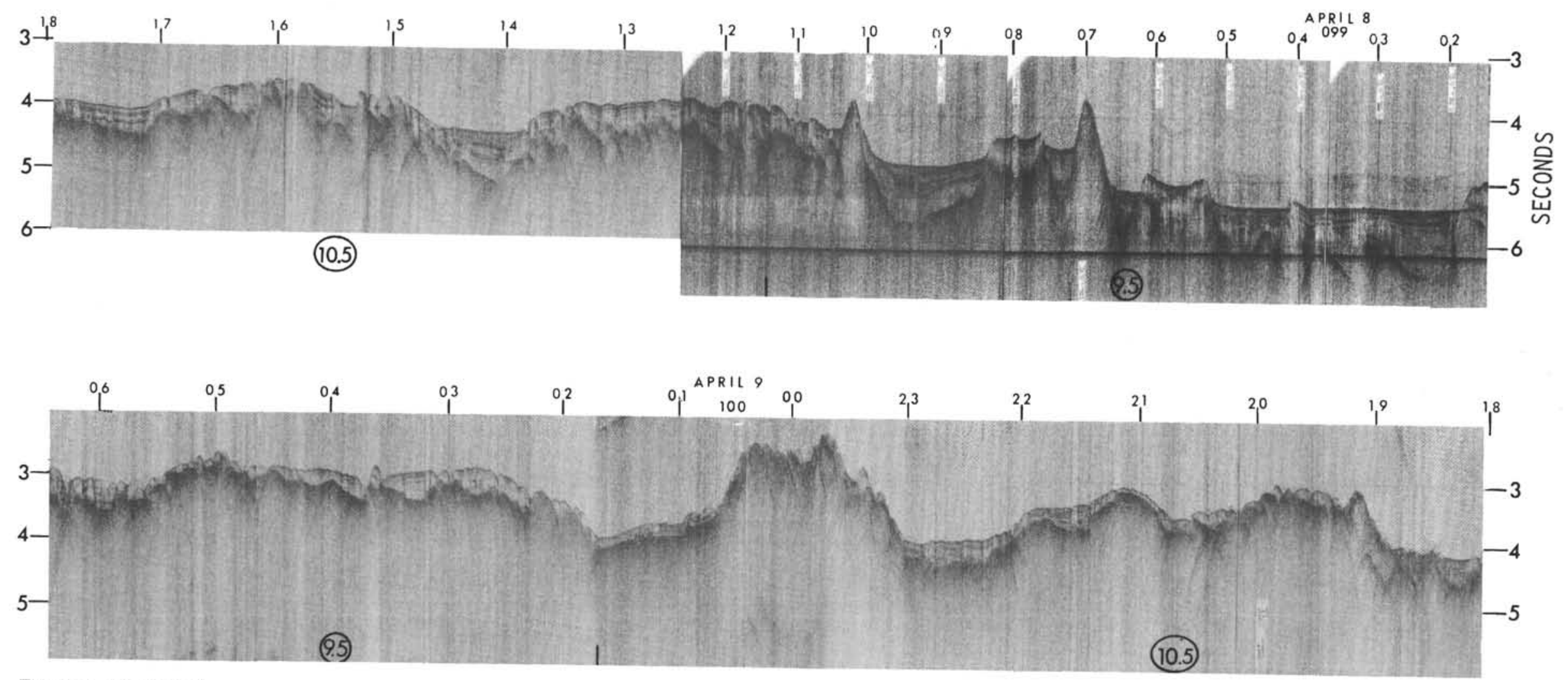

Figure 2. Continued 

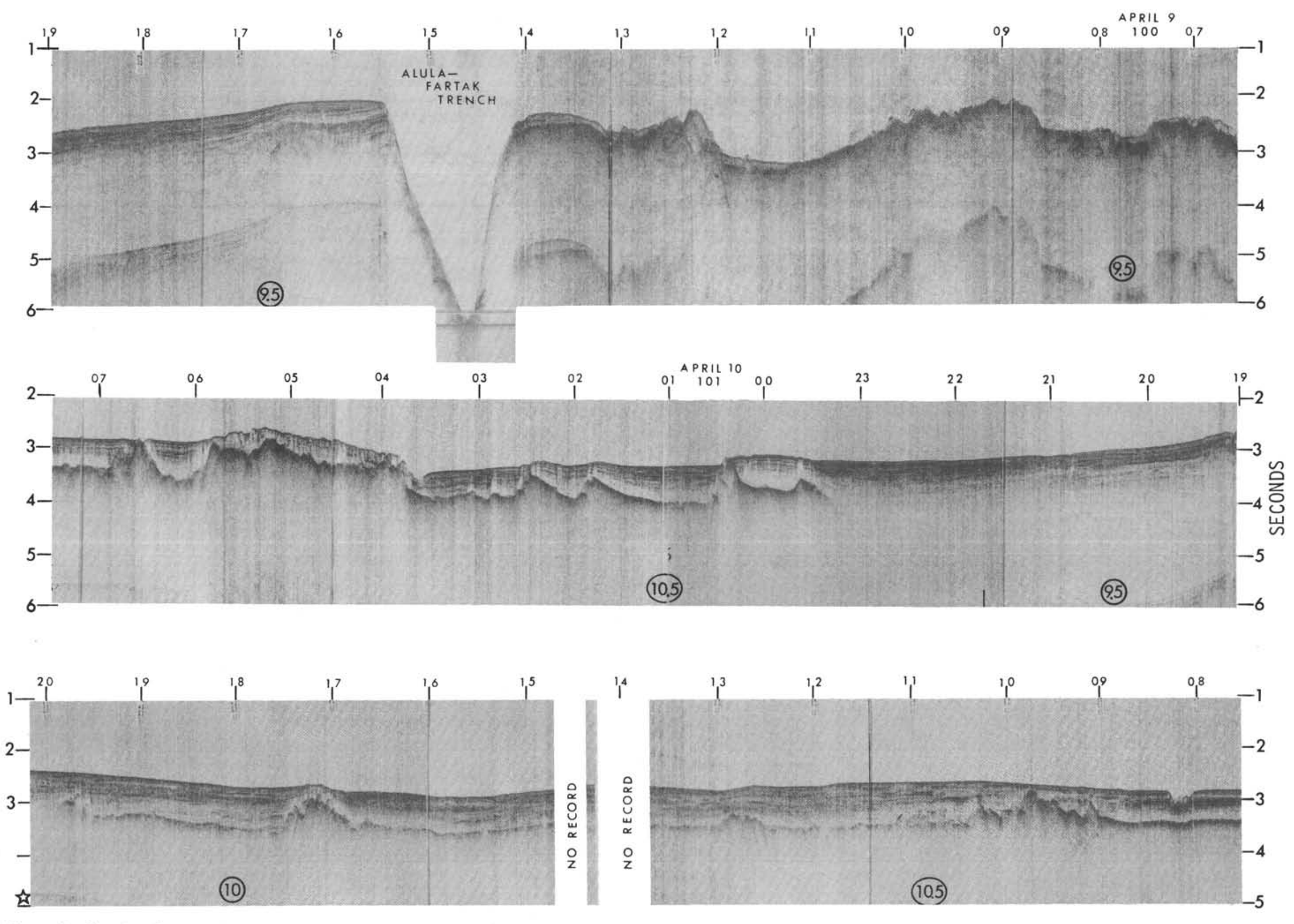

$\vec{\Xi}$ Figure 2. Continued

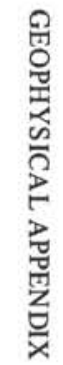


ప
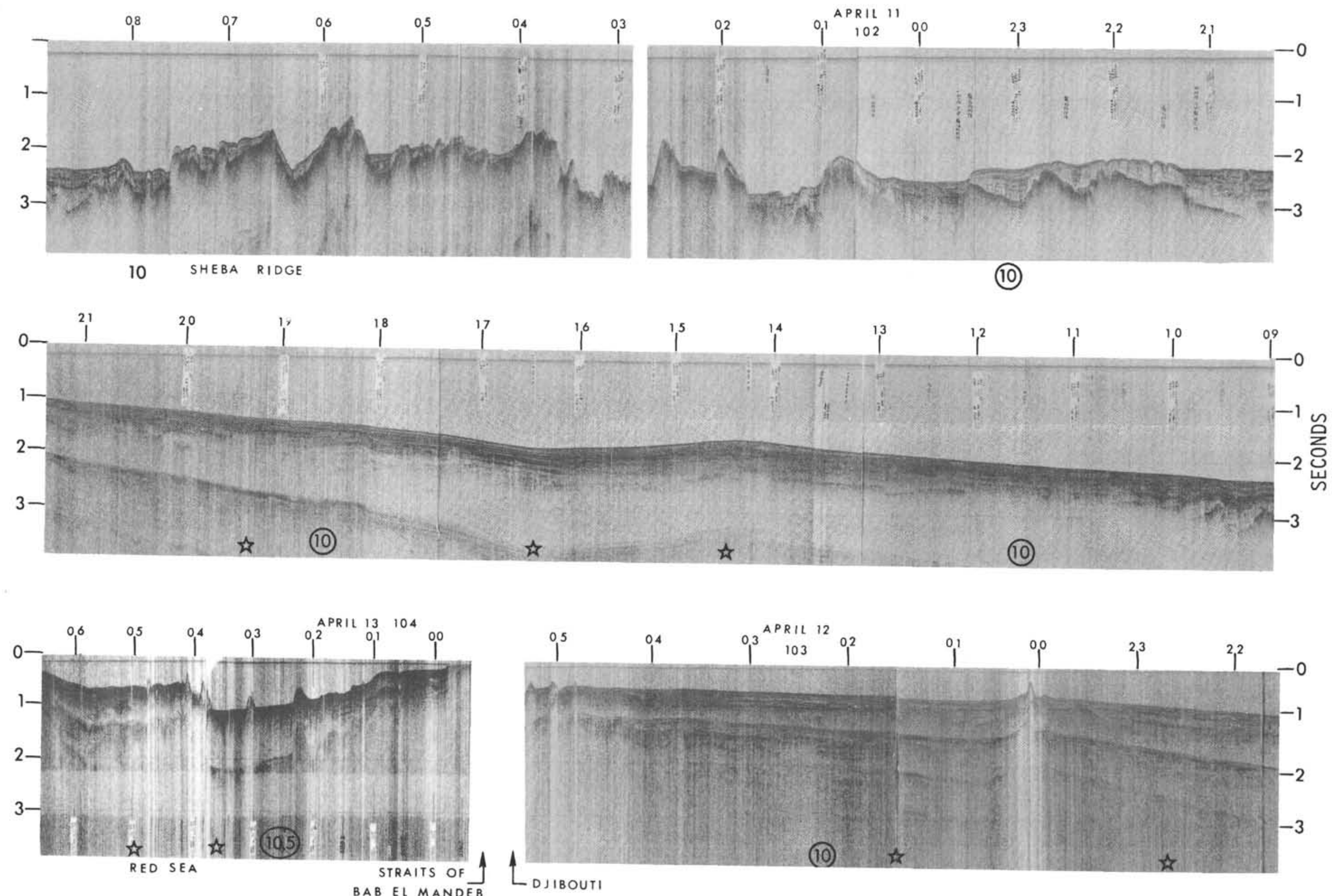

Figure 2. Continued 

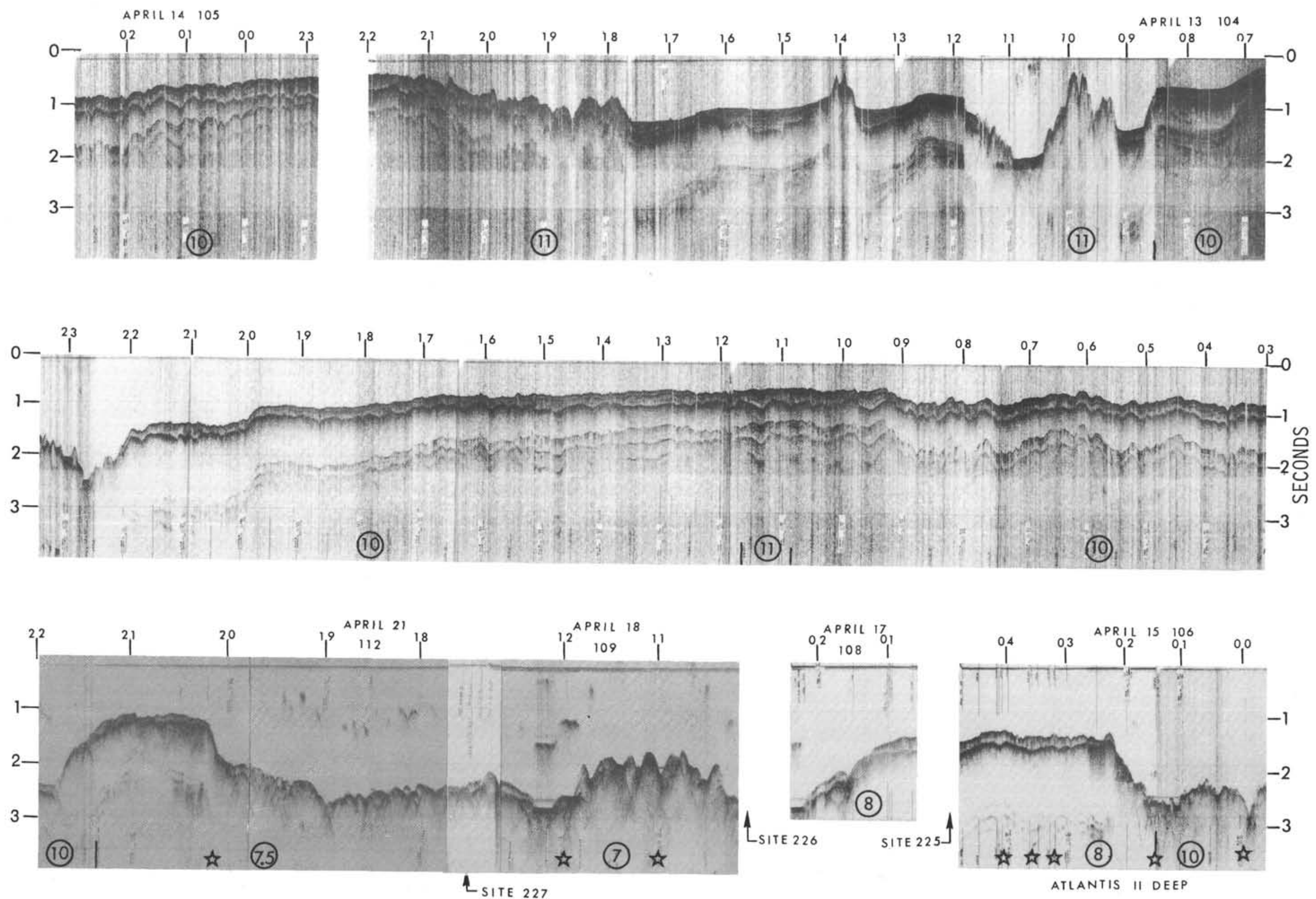
$\vec{\Xi}$
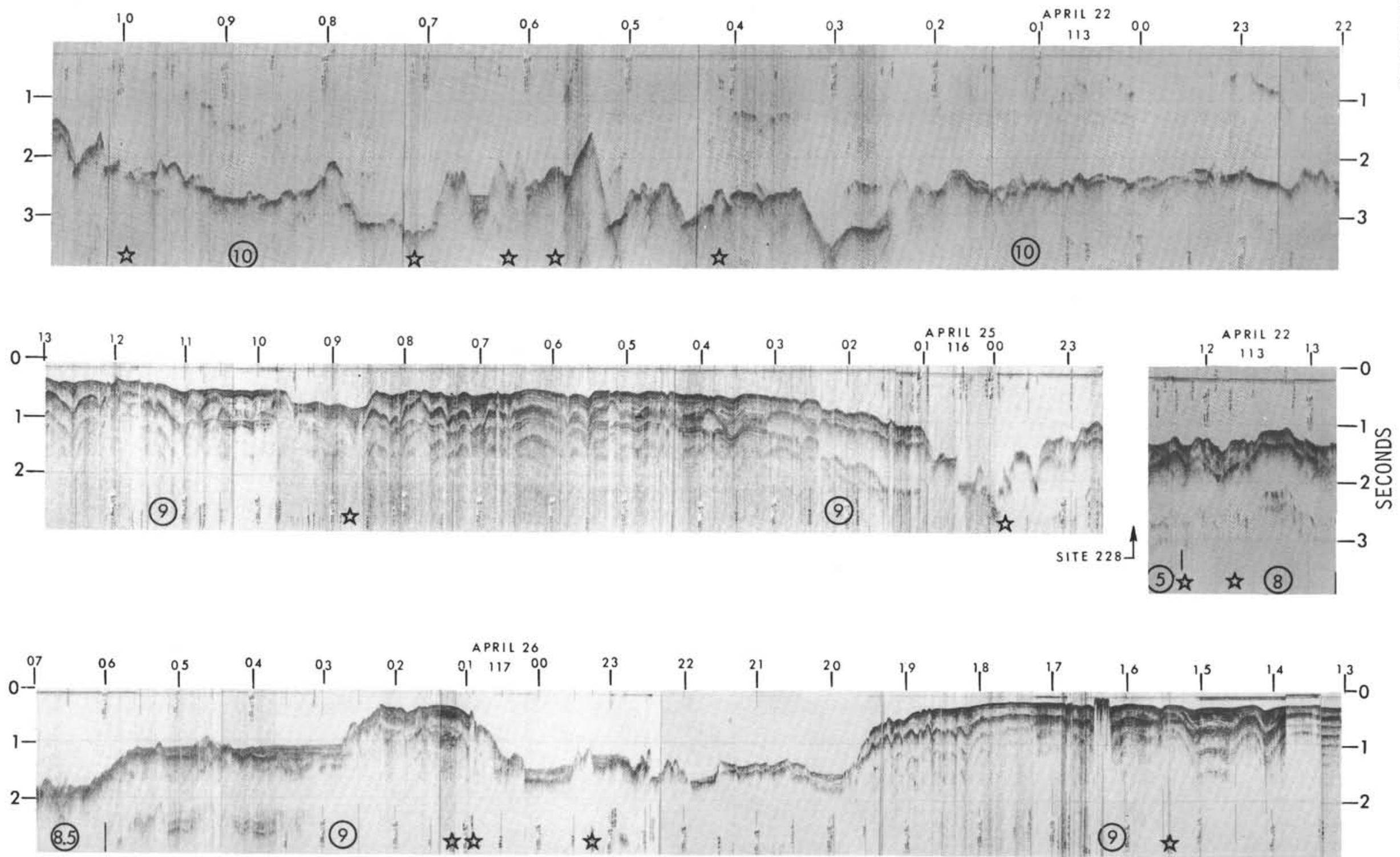

Figure 2. Continued 

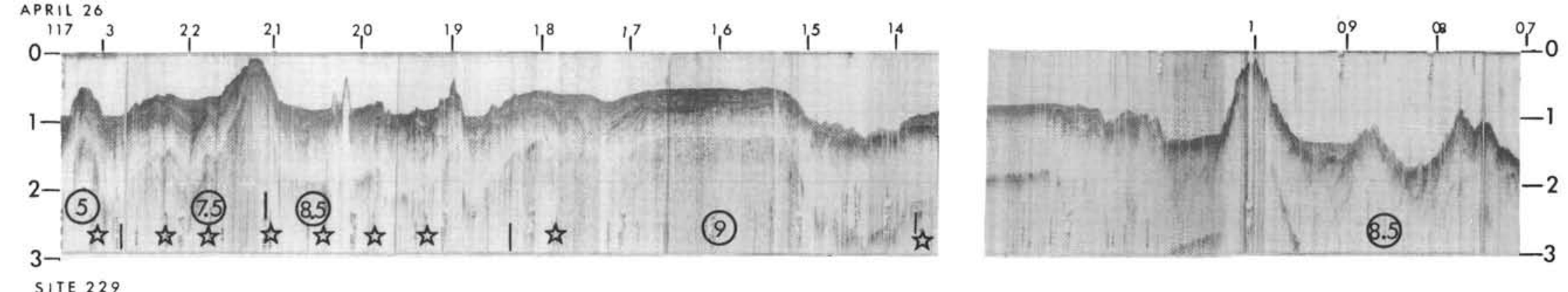
SITE 229

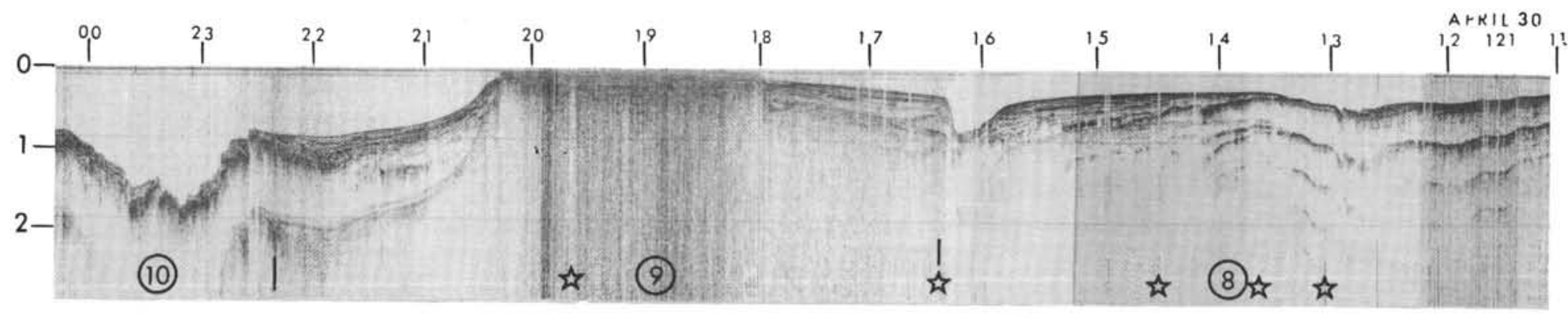

GULF OF ADEN

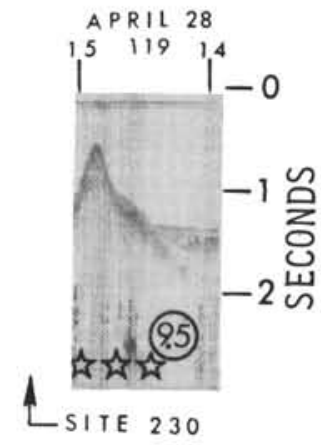

Figure 2. Continued

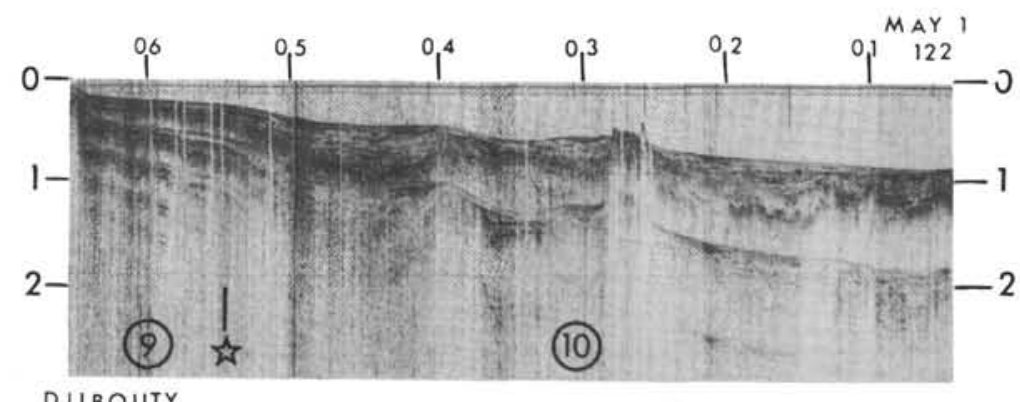

$\exists$ 